\title{
Panorama bibliométrico das teses e dissertações sobre educação indígena
}

\author{
Alexandre Masson Maroldi ${ }^{1}$, Luis Fernando Maia Lima ${ }^{2}$, Carlos Roberto Massao Hayashi ${ }^{3}$, Maria Cristina \\ Piumbato Innocentini Hayashi ${ }^{4}$ \\ ${ }^{1}$ Universidade Federal de Rondônia - UNIR. Departamento de Ciência da Informação. Campus BR 364, Km 9,5. \\ Porto Velho - RO. Brasil. alexandre@unir.br. ${ }^{2}$ Universidade Federal de Rondônia - UNIR. ${ }^{3}$ Universidade \\ Federal de São Carlos - UFSCAR. ${ }^{4}$ Universidade Federal de São Carlos - UFSCAR
}

RESUMO. A educação indígena no Brasil tem o seu marco fundador nas primeiras ações catequéticas dos jesuítas na segunda metade do século XVI. Nessa longa trajetória até os dias atuais a educação dos povos indígenas que habitam o território brasileiro tem sido alvo de controvérsias e discussões nos níveis governamental e acadêmico, o que tem gerado inúmeros estudos. Essa pesquisa teve como objetivo elaborar um panorama bibliométrico da produção científica sobre educação indígena presente nas teses e dissertações da Biblioteca Digital Brasileira de Tese e Dissertações (BDTD/IBICT) por meio da metodologia bibliométrica. $\mathrm{O}$ corpus analisado foi composto por 173 trabalhos de pós-graduação defendidos no país entre os anos de 1996 a 2016. Os resultados apontam que as regiões Sudeste e Sul, respectivamente, concentram o maior número de trabalhos e que a área da Educação é majoritária na produção científica das teses e dissertações recuperadas.

Palavras-chave: Educação Indígena, Bibliometria, Produção Científica. 


\title{
Bibliometric overview of thesis and dissertations on indigenous education
}

\begin{abstract}
The indigenous education in Brazil has its founding milestone in the first catechetical actions of the Jesuits in the second half of the sixteenth century. In this long trajectory up to the present day the education of the indigenous peoples that inhabit the Brazilian territory has been the subject of controversies and discussions at the governmental and academic levels, which has generated numerous studies. This research had as objective to elaborate a bibliometric panorama of the scientific production on indigenous education present in theses and dissertations of the Brazilian Digital Library of Thesis and Dissertations (BDTD/IBICT) through bibliometric methodology. The corpus analyzed was composed of 173 postgraduate studies defended in the country between 1996 and 2016. The results indicate that the Southeast and South regions, respectively, concentrate the largest number of papers and that the Education area is the majority in the Scientific production of the thesis and dissertations recovered.
\end{abstract}

Keywords: Indigenous Education, Bibliometric, Scientific Production. 


\section{Panorama bibliométrico de las tesis y disertaciones sobre educación indígena}

RESUMEN. La educación indígena en Brasil tiene su marco fundador en las primeras acciones catequéticas de los jesuitas en la segunda mitad del siglo XVI. En esta larga trayectoria hasta los días actuales la educación de los pueblos indígenas que habitan el territorio brasileño ha sido objeto de controversias y discusiones en los niveles gubernamental y académico, lo que ha generado innumerables estudios. Esta investigación tuvo como objetivo elaborar un panorama bibliométrico de la producción científica sobre educación indígena presentes en las tesis y disertaciones de la Biblioteca Digital Brasileña de Tesis y Disertaciones (BDTD/IBICT) por medio de la metodología bibliométrica. El corpus analizado fue compuesto por 173 trabajos de postgrado defendidos en el país entre los años 1996 a 2016. Los resultados apuntan que las regiones sudeste y sur, respectivamente, concentran el mayor número de trabajos y que el área de Educación es mayoritaria en la región producción científica de las tesis y disertaciones recuperadas.

Palabras clave: Educacion Indígena, Bibliometria, Producción Científica. 


\section{Introdução}

O Censo Escolar da Educação Básica referente ao período 2012 (Inep, 2013, p. 34) indicava a existência de 234.869 alunos indígenas, dos quais 167.338 estavam matriculados no ensino fundamental; 17.586 no ensino médio; 824 no Ensino de Jovens e Adultos (EJA) e 243 na Educação Especial. Em 2015, o Censo Escolar registrou a existência de 3.085 escolas indígenas, das quais 2.890 estão em terra indígena onde estão matriculados 262.328 alunos (Inep, 2016, p. 34).

Esse quadro demográfico atual sobre os indígenas no país serve como pano de fundo para introduzir o tema dessa pesquisa: a educação indígena. Tudo se inicia na segunda metade do século XVI quando chegaram ao país os primeiros jesuítas da Companhia de Jesus chefiados pelo padre Manoel da Nóbrega. Enviados de Portugal por D. João III, o objetivo desses missionários era converter os nativos à fé cristã. No entanto, a ação pedagógica desenvolvida pelos jesuítas não visava somente à catequização dos indígenas, mas era uma forma de inculcar a cultura letrada do colonizador, conforme argumentam os inúmeros estudiosos da educação jesuítica no Brasil colonial (Bittar \& Ferreira Jr., 2007; Faria, 2016).
Desde a escola catequizadora e civilizatória, passando pela criação do Serviço de Proteção ao Índio (SPI) em 1910, e pelas ações desenvolvidas pela Fundação Nacional do Índio (FUNAI) a partir de 1967, a educação indígena atingiu o ápice com a Constituição Federal de 1988, que garantiu os direitos dos indígenas e traçou "um quadro jurídico novo para a regulação das relações do Estado com as sociedades indígenas contemporâneas" rompendo, desse modo, "com uma tradição de quase cinco séculos de política integracionista, e reconhecendo aos índios o direito à prática de suas formas culturais próprias." (Alves, 2002, p. 20).

Desde então, a temática da educação indígena tem sido bastante explorada seja em relatórios técnicos produzidos por órgãos governamentais de planejamento e execução de políticas educacionais voltadas para essa população, seja em trabalhos acadêmicos que resultam de pesquisas realizadas em nível de pósgraduação ou em artigos divulgados em periódicos científicos. Em um balanço da produção científica sobre a educação indígena realizado por D’Angelis (2008, p.28), o autor chamava a atenção para o fato de que existe um grande volume de trabalhos sobre essa temática, contudo alertava que essas publicações "precisam 
ser lidas ou compreendidas no conjunto das demais para se construir, com isso, um painel dos caminhos e descaminhos da educação indígena no Brasil”.

Observa-se que a produção científica sobre a educação indígena tem ensejado vários estudos do tipo "estado da arte" que visam avaliar as tendências e perspectivas sobre essa temática, bem como identificar possíveis lacunas a serem preenchidas nessa subárea de conhecimento. Para Grupioni (2008, p. 21), "tais dados dariam força à proposição de que o tema da escola e da educação indígena ganhou legitimidade e importância na pesquisa acadêmica, tanto na área de educação como da antropologia”. Concorda-se, pois, com esses argumentos que reforçam a importância de analisar a produção científica sobre educação indígena. A análise desses estudos não só é oportuna e relevante, mas também oferece elementos importantes que contribuem para desvelar aspectos ainda obscuros sobre a educação indígena. Como recomenda Grupioni (2003), estes trabalhos deverão ir além de uma análise dos resumos das teses $\mathrm{e}$ dissertações sobre educação escolar indígena. Diante desses aspectos, esse artigo tem como objetivo apresentar um estudo bibliométrico da produção científica sobre educação indígena presente nas teses e dissertações da Biblioteca Digital
Brasileira de Tese e Dissertações (BDTD/IBICT).

\section{Procedimentos metodológicos}

A metodologia utilizada é a bibliometria, pois permite analisar a produção científica de campos de conhecimento específicos. Ademais, conforme sustentam Silva, Hayashi e Hayashi (2011), essa metodologia aplica métodos quantitativos para análises estatísticas de publicações e atividades científicas.

A fonte de dados foi a Biblioteca Digital Brasileira de Teses e Dissertações (BDTD) mantida pelo Instituto Brasileiro de Informação em Ciência e Tecnologia (IBICT) que reúne em um só portal as teses e dissertações defendidas em todo o País e por brasileiros no exterior. Para coleta de dados da pesquisa na base de dados da BDTD foram escolhidas as expressões "educação indígena" e “educação escolar indígena" extraídas da revisão de literatura que fundamentou a pesquisa que, embora representem conceitos diferentes, estão presentes na literatura que fundamenta o campo. Uma vez determinadas as duas expressões de busca estipularam-se os seguintes critérios para a seleção dos trabalhos: a) inclusão: todas as teses e dissertações que 
contivessem no título, palavras-chave ou resumo as expressões de busca, independentemente da área de conhecimento em que foram defendidas; $b$ ) exclusão: trabalhos que não possuíam acesso ao texto completo; registros duplicados e aqueles cujo escopo não se mostrou aderente ao tema pesquisado. Também não foi aplicado qualquer tipo de filtro de busca avançada ou mesmo a temporalidade dos registros selecionados, uma vez que a intenção é cartografar a evolução do tema ao longo dos anos. A coleta de dados foi realizada no dia 10 de dezembro de 2016 e após a aplicação dos critérios de inclusão e exclusão o corpus final da pesquisa visando à análise bibliométrica foi composto por 173 trabalhos defendidos entre os anos de 1996 a 2016, recuperados com o termo “educação indígena" $(\mathrm{n}=58)$ e "educação escolar indígena" $(\mathrm{n}=115)$.

\section{Evolução temporal e nível de titulação}

Os 173 trabalhos foram categorizados de acordo com o nível de titulação, e a Figura 1 apresenta sua distribuição temporal.

Figura 1 - Distribuição temporal das teses e dissertações.

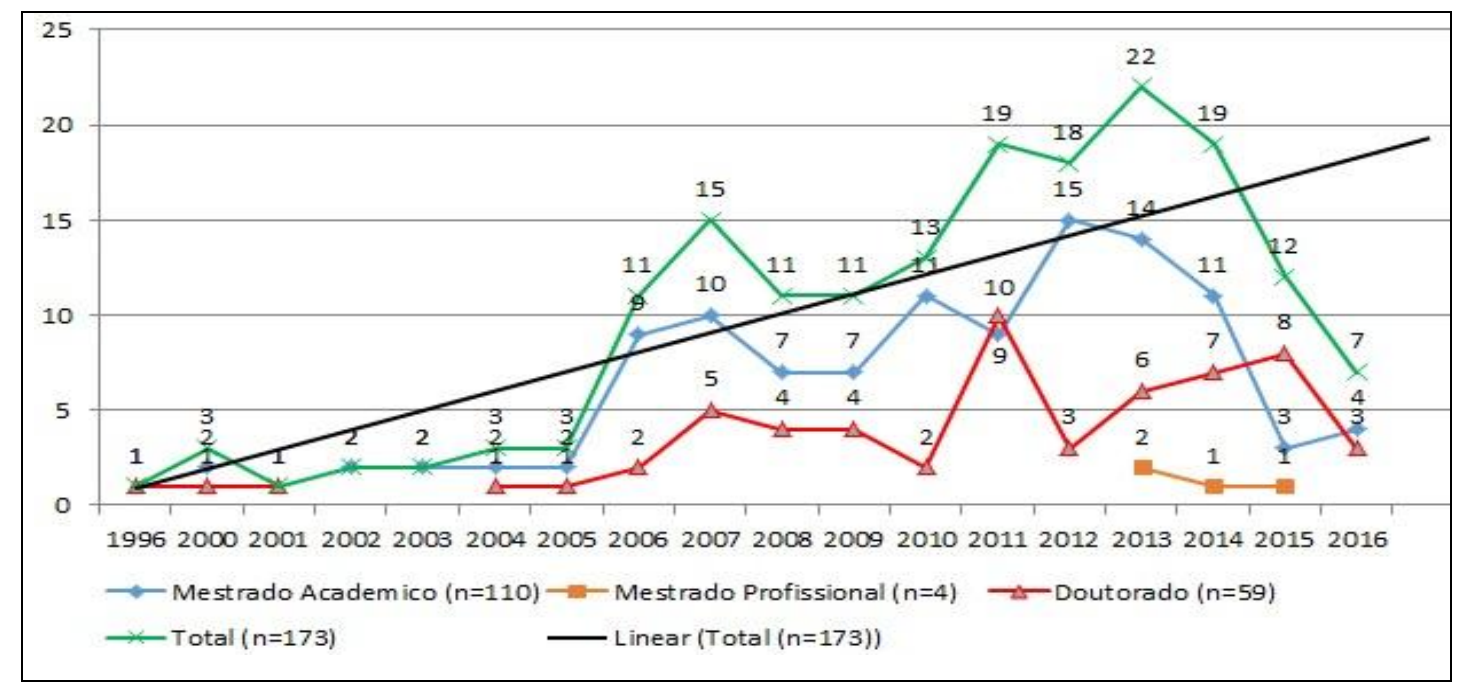

Fonte: Elaborada pelos autores.

De acordo com os dados da Figura 1, nota-se um desequilíbrio entre o total de dissertações de mestrado $(n=114)$ e o total de teses de doutorado $(n=59)$. Isto se deve, provavelmente, ao fato de que muitos pesquisadores que iniciaram suas pesquisas no mestrado com foco nos estudos sobre a educação indígena posteriormente mudaram seu escopo de interesse temático. Outra possível explicação é que após a 
defesa do mestrado alguns autores podem ter optado pela inserção no mercado profissional e não mais o caminho acadêmico. Além disso, de acordo com os dados da pós-graduação brasileira disponibilizados pela CAPES, o total de programas de doutorado $(n=64)$ é muito inferior ao total de programas de mestrado $(n=1.207)$ quando se considera apenas programas com apenas esses níveis (Geocapes, 2016) $^{\mathrm{i}}$, o que pode justificar o desequilíbrio no total de concluintes.

Observa-se na Figura 1 que não foi encontrado nenhum trabalho anterior ao ano de 1996. O primeiro trabalho identificado refere-se à tese de doutorado defendida no ano de 1996 por Terezinha de Jesus Machado Maher na Universidade de Campinas (UNICAMP) e tem como título: Ser professor sendo índio: questões de lingua(gem) e identidade. O objetivo da tese foi discutir os modos pelos quais as práticas discursivas dos participantes índios de um projeto de educação indígena na Amazônia ocidental refletem processos de (re)definição do que é ser, hoje, um professor-índio, tendo em vista o momento sócio-histórico.

Percebe-se na Figura 1 que há uma lacuna temporal nas produções acadêmicas entre os anos de 1997 até 1999. Nesse período não foram identificadas quaisquer dissertação e tese defendidas sobre educação indígena. Entretanto, nota-se que várias conquistas relativas à educação indígena foram alcançadas nesse período, como o Projeto de Declaração Interamericana sobre os Direitos dos Povos Indígenas que, em seu Artigo $9^{\circ}$, estabeleceu o direito aos povos indígenas de definir e aplicar seus próprios programas educacionais, bem como currículos e materiais didáticos e formação e capacitação para os docentes e administradores; por parte do MEC, que publicou em 1998 o Referencial Curricular Nacional para a Escola Indígena (RCNEI), entre outros. Ou seja, após ter se institucionalizado tais conquistas é que, de fato, inicia-se uma demanda de interesse pela temática no ambiente acadêmico.

Também quando se cruzam os dados da Figura 1 no recorte de tempo que vai de 1990 até 2003, observa-se uma semelhança entre os achados de nossa pesquisa com o trabalho de André (2009), que fez uma síntese comparativa da produção acadêmica dos pós-graduandos na área de Educação entre 1999 e 2003 com base nos resumos disponíveis no Banco de Dados da CAPES. A autora já havia notado um quase esquecimento de pesquisas relativas à temática da educação indígena no Brasil tanto no mapeamento que fez nos anos de 1990, quanto em seu mapeamento nos anos de 2000 . 
Nota-se também, ao observar a Figura 1, que entre os anos de 2000 e 2005 os trabalhos se mantêm sempre em níveis estáveis, embora baixos. No entanto, nesse período ocorreram importantes conquistas para os povos indígenas nas questões educacionais, como, por exemplo, 21 das 295 metas do Plano Nacional de Educação (PNE) de 2001 são referentes à modalidade da educação escolar indígena; e em 2002, foram organizados os Referenciais para a Formação de Professores Indígenas, entre outros avanços. Neste sentido, nossos achados induzem a pensar que tais conquistas podem ter suscitado na comunidade acadêmica o interesse pela temática elevando a procura pelos cursos de mestrado e doutorado. No entanto, como nos cursos de mestrado e doutorado as defesas costumam ocorrer após dois ou quatro anos, em média, do seu início acadêmico, os resultados dessas pesquisas nas produções científicas sobre o tema começam a aparecer a partir dos anos de 2006, quando há um incremento de trabalhos, como mostram os dados da Figura 1. Além disso, destaca-se que a partir do ano de 2005 começam a ser defendidos os primeiros trabalhos acadêmicos realizados por indígenas. (Luciano, 2011).

Observando novamente a Figura 1, nota-se que a partir do ano de 2009 até o ano de 2013, houve um aumento nas defesas de mestrado. Tal aumento pode ser reflexo do lançamento, em 2009, do edital Observatório da Educação Escolar Indígena elaborado pela CAPES em parceria com a Secretaria de Educação Continuada, Alfabetização e Diversidade (SECAD) e o Instituto Nacional de Estudos e Pesquisas Educacionais Anísio Teixeira (INEP). O edital convidou as Instituições de Ensino Superior (IES) a apresentarem projetos de estudos e pesquisas em educação indígena e entre seus principais objetivos estava o de fomentar o desenvolvimento de estudos e pesquisas na área, ampliar programas de pós-graduação stricto sensu na temática da educação intercultural indígena e fortalecer a identidade e a expansão da carreira docente na educação básica e superior intercultural. (Clímaco, Neves \& Lima, 2012).

A Figura 1 ainda mostra que somente a partir do ano de 2013 iniciam-se as produções oriundas dos programas de mestrado profissional, com dois trabalhos e nos dois anos seguintes um trabalho em cada ano totalizando quatro trabalhos no período entre 2013 e 2015.

Áreas de conhecimento e programas de pós-graduação 
De acordo com a Tabela 1, os resultados da pesquisa apontaram que as dissertações de mestrado $(n=114)$ e as teses de doutorado $(n=59)$ foram defendidas em vários programas de pós-graduação $(\mathrm{n}=29)$ do país vinculados a diferentes áreas de conhecimento ${ }^{\mathrm{ii}}$.

Tabela 1 - Distribuição dos trabalhos por área de conhecimento e programas de pós-graduação.

\begin{tabular}{|c|c|c|c|}
\hline $\begin{array}{c}\text { Áreas de } \\
\text { Conhecimento }\end{array}$ & Programas de Pós-Graduação & Teses & Dissertações \\
\hline \multirow{13}{*}{$\begin{array}{l}\text { Ciências Humanas } \\
\qquad(\mathrm{n}=136)\end{array}$} & 1. Educação & 30 & 66 \\
\hline & 2. Educação Escolar & 2 & 0 \\
\hline & 3. Educação Especial & 2 & 0 \\
\hline & 4. Gestão e Avaliação da Educação Pública & 0 & 1 \\
\hline & 5. Antropologia & 2 & 8 \\
\hline & 6. Antropologia Social & 1 & 4 \\
\hline & 7. Ciência Política & 2 & 0 \\
\hline & 8. História & 1 & 3 \\
\hline & 9. Geografia Humana & 1 & 0 \\
\hline & 10. Psicologia & 1 & 1 \\
\hline & 11. Ciências Sociais & 2 & 3 \\
\hline & 12. Teologia & 1 & 4 \\
\hline & 13. Ciências da Religião & 1 & 0 \\
\hline \multirow{3}{*}{ Ensino } & 14. Educação Matemática & 1 & 1 \\
\hline & 15. Educação em Ciências e Matemática & 0 & 2 \\
\hline & 16. Ensino de Ciências e Matemática & 0 & 1 \\
\hline \multirow{6}{*}{$\begin{array}{c}\text { Linguística, Letras e } \\
\text { Artes }\end{array}$} & 17. Letras & 1 & 5 \\
\hline & $\begin{array}{l}\text { 18. Estudos Linguísticos e Literários em } \\
\text { Inglês }\end{array}$ & 1 & 0 \\
\hline & 19. Letras e Linguística & 1 & 0 \\
\hline & 20. Linguística & 8 & 3 \\
\hline & 21. Artes Cênicas & 1 & 0 \\
\hline & 22. Música & 0 & 1 \\
\hline \multirow{2}{*}{$\begin{array}{l}\text { Ciências Sociais } \\
\text { Aplicadas }\end{array}$} & 23. Administração & 0 & 2 \\
\hline & 24. Direito & 0 & 1 \\
\hline Ciências Ambientais & 25. Desenvolvimento Sustentável & 0 & 4 \\
\hline \multirow{4}{*}{ Interdisciplinar } & 26. Desenho, Cultura e Interatividade & 0 & 1 \\
\hline & 27. Educação, Arte e História da Cultura & 0 & 1 \\
\hline & 28. Estudos Comparados sobre as Américas & 0 & 1 \\
\hline & 29. Políticas Públicas & 0 & 1 \\
\hline Total & & 59 & 114 \\
\hline
\end{tabular}

Fonte: Elaborada pelos autores.

O destaque da Tabela 1 são os trabalhos na área de Ciências Humanas $(n=136)$ representando $78,6 \%$ do total, sendo que a maioria $(\mathrm{n}=96)$ foi defendida em programas de pós-graduação em Educação, enquanto que os demais $(n=5)$ são em Educação Especial $(n=2)$, Educação Escolar $(n=2)$ e Gestão e 
Avaliação da Educação Pública $(n=1)$.

Esses resultados apontam que, além de mostrar o acerto na escolha das palavraschave para acessar a base da BDTD para recuperação dos trabalhos sobre educação indígena, sinaliza a contribuição dos programas de pós-graduação da área de Educação para a temática pesquisada. Ademais, caso fossem somados esses trabalhos dos programas de pós-graduação de Educação com aqueles da área de Ensino (n=5), que abordam as práticas educativas do ensino de ciências e matemática na educação indígena, juntos alcançariam 61,3\% (n=106) do total.

Em segundo lugar, na área de Ciências Humanas, destacam-se as contribuições da área de Antropologia $(n=15)$ representando $8,7 \%$ do total de trabalhos, corroborando o argumento de Bergamaschi (2012, p. 10) de que os estudos dos processos educacionais dos povos indígenas "constituíam-se ocupação de antropólogos" desde a década de 1980. Grupioni (2013, p. 79) parece concordar com esse argumento ao afirmar que juntamente com outros profissionais que atuam nos processos formativos de professores indígenas "os antropólogos podem fazer uma diferença importante e marcar sua contribuição no diálogo com a Educação”. Contudo, em suas reflexões o autor também observa que
... se os antropólogos tiveram papel importante no desenho inicial de práticas de formação interculturais, em oposição ao modelo integrador que o Estado propagava; e, se tiveram papel central na configuração de uma nova política pública para a educação escolar indígena, esta, ao ser implementada, acabou por alijálos do processo (Grupioni, 2013, p. 79).

Na visão do autor, "no encontro entre a Educação e a Antropologia nos processos de formação de professores indígenas, os antropólogos têm que evidenciar sua contribuição, e isso não está dado de antemão". (Grupioni, 2013, p. 79).

Por sua vez, Araújo (2014) estudou a produção científica das teses e dissertações sobre a infância indígena no Brasil no período entre 2001 e 2012, e concluiu que apenas 7,93\% dos trabalhos foram produzidos nos programas de pósgraduação em Antropologia em contraposição aos $31,74 \%$ defendidos em programas da área de Educação. Tassinari (2001, p. 48), também já alertava que a maioria dos trabalhos antropológicos não está atenta à questão da educação escolar devido "à impressão geral e difusa de que essa instituição permanece alheia à vida da aldeia e à respectiva cultura indígena”. Ou seja, os resultados da nossa pesquisa parecem confirmar as premissas das pesquisas de Araújo (2014), Grupioni (2013) e Tassinari (2001) de que a 
Antropologia cada vez mais tem se afastado das questões educacionais indígenas.

Os demais resultados da Tabela 1 mostram que na área de Ciências Humanas os trabalhos em programas de Ciências Sociais $(n=5)$, Ciência Política $(n=2)$, Teologia $(n=5)$, Ciências da Religião $(n=1)$, História $(n=4)$, Psicologia $(n=2)$ e Geografia Humana ( $\mathrm{n}=1)$ representaram $11,6 \%(n=20)$ do total.

Ressaltam-se os baixos índices na área de Geografia, uma vez que no campo da educação indígena a Geografia é um tema presente desde o ano de 1994, com a tese de doutorado de Márcia Spyer Resende (de 1994) intitulada Um mapa do que pode ser a geografia nas escolas indígenas, que teve como objetivo auxiliar na construção de uma proposta experimental de Programa de Geografia destinado à formação de professores indígenas. Além disso, como comentam Magalhães e Landim Neto (2013, p. 84) nas visões plurais sobre a educação indígena "perpassam elementos da Geografia calcados tanto em elementos jurídicos e institucionais como no cotidiano dos povos indígenas". Outro estudo também defende que a Geografia está diretamente relacionada com a educação indígena
... no momento em que ela se torna libertadora e autônoma, podendo tornar o sujeito dono de sua própria história e compreensão do ser e querer ser indígena e por meio do conhecimento do território que é imprescindível para a sobrevivência física e cultural. Cultura e território são indissociáveis. A categoria território é o elo que poderíamos chamar de geografia na concepção da ciência ocidental e na concepção os povos indígenas na qual depende não apenas a sobrevivência bem como o princípio para autonomia (Fontes, 2016, p. 66).

Os resultados da Tabela 1 também mostram que é escassa a produção de teses e dissertações no campo da Psicologia $(n=2)$, coincidindo com os achados do estudo de Oliveira e Zibetti (2015), que analisaram 129 trabalhos e só identificaram três oriundos de programas da área de Psicologia, levando-as a indagar:

Seria esse resultado decorrente da falta de interesse dos programas de pós-graduação em psicologia pela temática? Ou seria em decorrência de procedimentos éticos e burocráticos, que demandam muito tempo para aprovação dos projetos que envolvem populações indígenas nos comitês de ética? (Oliveira \& Zibetti, 2015, p. 109).

Uma possível resposta para estas questões pode ser encontrada em Ferraz e Domingues (2016) que realizaram um estado da arte sobre a presença dos povos indígenas na Psicologia brasileira em artigos indexados nas bases de dados SciELO e PePSIC, e verificaram que 
apesar dos artigos encontrados se caracterizarem pela interdisciplinaridade também eram escassas as referências específicas da área de Psicologia, o que as levou a concluir que

... ainda temos muito a avançar, possivelmente pela aproximação recente da Psicologia com o estudo da temática e também pela própria constituição da Psicologia enquanto ciência pautada principalmente por tradições individualistas, que destoam das tradições indígenas que se baseiam principalmente no coletivismo (Ferraz \& Domingues, 2016, p. 682).

Por sua vez, outras áreas como o Direito $(n=1)$, as Artes Cênicas $(n=1)$ e a Música (n=1) também apresentaram os mais baixos índices de trabalhos. A história da educação escolar indígena no país foi marcada por inúmeras Leis e Decretos, no entanto, mesmo com todos os avanços ou retrocessos sobre os direitos indígenas, principalmente após a década de 1970, os achados da pesquisa parecem sugerir que ainda não foram suficientes para despertar na comunidade científica da área do Direito um interesse em desenvolver pesquisas com esta temática, haja vista que a Tabela 1 aponta a existência de apenas um trabalho. O mesmo total foi obtido para trabalhos em programas de pós-graduação na área das Artes Cênicas $(n=1)$ e da Música $(n=1)$, a despeito das raízes históricas da música e do teatro na educação indígena, conforme argumentam Bittar e Ferreira Junior (2007), ao mostrarem a importância do teatro anchietano na catequese e pedagogia jesuítica desde a chegada dos jesuítas no país no século XVI.

Os resultados obtidos também mostraram a existência de trabalhos sobre educação indígena oriundos de programas de pós-graduação da área Teologia $(n=5)$, Desenvolvimento Sustentável $(n=4)$ e Administração $(n=2)$.

Os dados da Tabela 1 ainda apontam que os trabalhos de pós-graduação da área de Linguística e Letras $(n=19)$ representaram $10,9 \%$ do total. No campo da Linguística e Letras, o estudo das relações entre essas áreas vem desde o final dos anos 1960, com a implantação pela FUNAI do ensino bilíngue nas comunidades indígenas. No âmbito acadêmico, vale ressaltar que inúmeros autores desses campos de conhecimento deram importantes contribuições consolidadas em vigorosa produção de livros e artigos sobre leitura e escrita em sociedades indígenas. De certo modo, também deve ter sido um atrativo para os pesquisadores dessa área os materiais didáticos para a formação de professores indígenas, incluindo livros, dicionários, entre outros, que foram publicados para atender às exigências tanto da LDB como 
do PNE, suscitando diversos estudos de análises linguísticas desenvolvidos nos programas de pós-graduação da área.

Ao compulsar a literatura sobre a temática da educação indígena verificou-se que alguns estudos alertavam sobre o tímido envolvimento da área de Educação com a questão indígena. Contudo, diante dos resultados obtidos nessa pesquisa notase que esse cenário apresentou mudanças. Por exemplo, na segunda metade dos anos 1990, Kahn e Franchetto (1994, p. 7) enfatizavam que ainda era "muito tímida a inserção de pedagogos na área" diante da mobilização da sociedade para a "recuperação da identidade étnica dos povos indígenas" que acontecia principalmente nas universidades:

... centros e cursos de linguística incrementam os levantamentos e estudos das línguas indígenas; antropólogos subsidiam projetos de educação escolar indígena (geralmente encaminhados por agências não governamentais); matemáticos, geógrafos e historiadores dedicam-se cada vez mais aos estudos do que se passou a designar por Etnoconhecimentos (Kahn, Franchetto, 1994, p. 7).

Passados dezessete anos, Calderón e Ferreira (2011) assinalam a ausência de interesse da área de Administração da Educação para o estudo de políticas, programas e projetos na área de educação indígena. $\mathrm{Na}$ visão dos autores, uma possível explicação para a ausência de acolhida

... possa ser encontrada na relação histórica existente entre a área da educação/pedagogia com a questão indígena, a mesma que no contexto das lutas pelos direitos das comunidades indígenas tem sido muito frágil, perdendo espaço para a antropologia e as ciências sociais (Calderón \& Ferreira, 2011, p. 336).

São questões instigantes. No entanto, considerando os resultados obtidos na pesquisa realizada outro cenário foi desvelado, pois a área de Educação é a que tem atraído o maior número de interessados nas questões relativas ao contexto da educação indígena no Brasil.

\section{Instituições, regiões do país e dependência administrativa}

A pesquisa também analisou a distribuição dos trabalhos $(\mathrm{n}=173)$ nos programas de pós-graduação vinculando-os às instituições, regiões do país e dependência administrativa.

A Tabela 2 apresenta a distribuição dos trabalhos de acordo com o total de IES identificadas $(n=39)$ ressalvando que nesse total a Universidade Estadual Paulista “Julio de Mesquita Filho" (UNESP) só foi contabilizada uma única vez, pois é uma instituição multicampi e seus programas de pós-graduação pertencem a unidades distintas. 
DOI: http://dx.doi.org/10.20873/uft.2525-4863.2017v2n2p677

Tabela 2 - Distribuição dos trabalhos por instituições de ensino superior.

\begin{tabular}{|c|c|c|}
\hline Siglas & Instituições & Trabalhos \\
\hline UFRGS & Universidade Federal do Rio Grande do Sul & 23 \\
\hline PUC-SP & Pontifícia Universidade Católica de São Paulo & 20 \\
\hline USP & Universidade de São Paulo & 16 \\
\hline Unicamp & Universidade Estadual de Campinas & 11 \\
\hline UnB & Universidade de Brasília & 10 \\
\hline UFSCar & Universidade Federal de São Carlos & 6 \\
\hline UFSC & Universidade Federal de Santa Catarina & 6 \\
\hline UFPE & Universidade Federal de Pernambuco & 6 \\
\hline UFMG & Universidade Federal de Minas Gerais & 5 \\
\hline EST & Escola Superior de Teologia da São Leopoldo & 5 \\
\hline FURB & Universidade Regional de Blumenau & 5 \\
\hline UFBA & Universidade Federal da Bahia & 5 \\
\hline UFMS & Universidade Federal do Mato Grosso do Sul & 4 \\
\hline UFS & Universidade Federal do Sergipe & 4 \\
\hline$\overline{U F J F}$ & Universidade Federal de Juiz de Fora & 3 \\
\hline UFPR & Universidade Federal do Paraná & 3 \\
\hline UFRN & Universidade Federal do Rio Grande do Norte & 3 \\
\hline UFGD & Universidade Federal da Grande Dourados & 3 \\
\hline UFPA & Universidade Federal do Pará & 3 \\
\hline FGV-EAESP & Fundação Getúlio Vargas - São Paulo & 2 \\
\hline UMESP & Universidade Metodista de São Paulo & 2 \\
\hline UNESP - Rio Claro & Universidade Estadual Paulista - Rio Claro & 2 \\
\hline UNESP-Araraquara & Universidade Estadual Paulista- Araraquara & 2 \\
\hline UNISINOS & Universidade do Vale do Rio do Sinos & 2 \\
\hline UFSM & Universidade Federal de Santa Maria & 2 \\
\hline UFAL & Universidade Federal do Alagoas & 2 \\
\hline UFMA & Universidade Federal do Maranhão & 2 \\
\hline UFPB & Universidade Federal da Paraíba & 2 \\
\hline PUC-GO & Pontifícia Universidade Católica de Goiás & 2 \\
\hline UFG & Universidade Federal de Goiás & 2 \\
\hline UNISANTOS & Universidade Católica de Santos & 1 \\
\hline PUC/Camp. & Pontifícia Universidade Católica de Campinas & 1 \\
\hline UNINOVE & Universidade Nove de Julho & 1 \\
\hline UNOESTE & Universidade do Oeste Paulista & 1 \\
\hline UPM & Universidade Presbiteriana Mackenzie & 1 \\
\hline PUC-RS & Pontifícia Universidade Católica do Rio Grande do Sul & 1 \\
\hline UEL & Universidade Estadual de Londrina & 1 \\
\hline UFRPE & Universidade Federal Rural de Pernambuco & 1 \\
\hline UEFS & Universidade Federal de Feira de Santana & 1 \\
\hline $\mathrm{UCDB}$ & Universidade Católica Dom Bosco & 1 \\
\hline \multicolumn{2}{|l|}{ TOTAL } & 173 \\
\hline
\end{tabular}


Fonte: Elaborada pelos autores.

As IES com o maior número de trabalhos foram UFRGS $(n=23)$, PUC-SP $(\mathrm{n}=20)$, USP $(\mathrm{n}=16)$, Unicamp $(\mathrm{n}=11)$ e UnB $(n=10)$. O elevado número de teses e dissertações sobre educação indígena na UFRGS se deve ao fato de existir no Programa de Pós-Graduação em Educação (PPGE) uma área temática de pesquisa que investiga os processos de educação indígena, a relação entre as práticas educativas tradicionais, as cosmologias indígenas e as escolas nas aldeias, as afinidades entre saberes e conhecimentos indígenas e não indígenas, as marcas ameríndias no fazer educativo da nossa sociedade, bem como a ética do cuidado nas práticas que mobilizam a memória e a tradição na formação de professores e no ensino de história (UFRGS, 2017). Nessa área temática foram defendidos oito dentre os 23 trabalhos identificados na pesquisa. O mesmo ocorre na PUC-SP, cuja linha de pesquisa "Processos de escolarização, desigualdades sociais e diversidade" de seu PPGE desenvolve estudos sobre "escolas das comunidades dos distintos grupos étnico-culturais, dentre os quais os das comunidades indígenas e quilombolas." (PUC-SP, 2017).

Por sua vez, como refere Silva (2016, p. 52) na USP e na Unicamp estão localizados os "maiores centros de estudos antropológicos e boa parte das pesquisas envolvendo povos indígenas, consequentemente sobre escolarização". Ademais, como observaram Souza e Bruno (2015) tais universidades também têm contribuído com assessorias especializadas, elaborando propostas educativas para atendimento das necessidades e interesses dos indígenas, e promovido ações de formação de professores indígenas para o desenvolvimento pedagógico em suas aldeias $\mathrm{Na}$ visão desses autores, essas instituições ainda "buscam respaldo para novas políticas públicas a fim de que, sucessivamente, os indígenas tenham em suas aldeias, escolas de qualidade que atendam as especificações existentes". (Souza \& Bruno, 2015, p. 5).

Também é válido assinalar que a USP e a Unicamp são as instituições que sediam grupos de pesquisa com produção científica de referência na área dos estudos indígenas, como o Grupo de Educação Indígena (MARI/USP) e o Núcleo de Educação e Cultura e Educação Indígena da Associação Brasileira de Leitura, sediado na Unicamp.

$\mathrm{Na}$ UnB o total de trabalhos $(\mathrm{n}=10)$ está distribuído em seis programas de pós- 
graduação, mas nenhum deles é na área de Educação: Ciências Ambientais $(\mathrm{n}=4)$; Antropologia ( $n=2)$ e Linguística, Ciências Sociais, Música e Estudos Comparados sobre as Américas, cada um com apenas um trabalho, o que demonstra a interdisciplinaridade no estudo da educação indígena.

Juntas essas cinco instituições UFRGS, PUC-SP, USP, Unicamp e UnB respondem por $46,2 \%$ de toda produção $(n=80)$ de teses ou dissertações sobre educação indígena. As demais instituições $(n=34)$ responderam por $53,8 \%(n=93)$ do total de trabalhos. Portanto, se por um lado há concentração de trabalhos em poucas instituições, por outro, os resultados apontaram uma dispersão da produção de teses e dissertações em inúmeras IES.

Com relação às regiões do país, a região Sudeste $(n=74)$ e Sul $(n=48)$ apresentam uma maior concentração de teses e dissertações reunindo 70,5\% do total, e em seguida as regiões Nordeste $(n=26)$ e Centro-Oeste $(n=22)$, respectivamente com $15 \%$ e $12,7 \%$, sendo que a região Norte $(\mathrm{n}=3)$ reuniu $1,7 \%$ do total.

Esses resultados revelam algumas características interessantes da produção científica sobre a educação indígena. Em primeiro lugar, reproduzem as assimetrias regionais e estaduais presentes no sistema nacional de pós-graduação do país, conforme argumentam Guimarães et al. (2015). Ao reunirem o maior número de trabalhos à pós-graduação, as regiões Sudeste e Sul do país representam o forte domínio histórico dessas regiões sobre as demais, não só como centros econômicos, mas, também, de produção de conhecimento, carreando a maior parte dos recursos da CAPES que atendem aos requisitos necessários para execução dos diversos programas implementados por essa agência nesta região do país (Souza \& Pereira, 2002).

Em segundo lugar, a região Norte reúne o maior contingente populacional de povos indígenas, e ainda concentra mais da metade das escolas indígenas do país e grande parte das etnias indígenas existentes no território nacional; no entanto, é a que apresentou o menor número de estudos.

Embora estivessem se referindo à análise da produção científica em Administração da Educação, o argumento de Calderón e Ferreira (2011) pode ser aplicado ao exíguo número de teses e dissertações sobre educação indígena oriundas de instituições da região Norte encontrado em nossa pesquisa. Dizem os autores:

O fato da maior produção científica no Brasil estar concentrada na região sudeste do país não é justificativa 
para eximir os pesquisadores da área da Administração da Educação da produção de estudos focados na questão indígena, como se essas comunidades somente existissem num lugar distante, lá longe, na Amazônia. Comunidades desse tipo também existem na região sudeste, mesmo assim, a literatura acadêmica revela certa distância da elite intelectual na área da educação em relação às políticas públicas educacionais na área indígena, fato evidenciado também na inexistência de um grupo de trabalho específico na Associação Nacional de Pós-Graduação e Pesquisa em Educação (ANPEd) (Calderón \& Ferreira, 2011, p. 336).

Acresce a isso que os cursos de pósgraduação da região Norte no Brasil ainda não estão totalmente consolidados. Porém, outro aspecto é relevante nessas discussões. Desde o ano 2007 a CAPES realiza chamadas públicas para o recebimento de projetos de implantação de redes de cooperação acadêmica, visando à formação de pessoal nas modalidades de Mestrados e Doutorados Interinstitucionais (MINTER e DINTER) que são compostas de turmas de mestrado e de doutorado conduzidas por uma instituição promotora nacional nas dependências de uma instituição de ensino e pesquisa receptora, localizada em regiões, no território brasileiro ou no exterior, afastadas de centros consolidados em ensino e pesquisa. A instituição promotora é responsável por garantir o nível de qualidade das atividades de ensino e pesquisa desenvolvidas por seu programa de pós-graduação na instituição receptora (CAPES, 2017).

Se por um lado estes programas Interinstitucionais qualificam o corpo docente das instituições receptoras, de outro lado, quando se considera a produção dos trabalhos acadêmicos o abismo só aumenta. Ou seja, muitas vezes as dissertações e as teses defendidas nas regiões Norte e Nordeste do país, justamente as regiões que mais recebem propostas de DINTER, abordam as problemáticas locais, porém suas produções são contabilizadas para a Instituição promotora, geralmente uma IES do Sudeste ou Sul do Brasil, o que, neste sentido, só aumenta a assimetria na produção científica entre as regiões. Neste sentido, e considerando os resultados da presente pesquisa, concorda-se com FéresCarneiro et al. (2010) de que as políticas públicas de pesquisa e pós-graduação, em parte executadas pela CAPES para favorecer a descentralização e o crescimento da Pós-Graduação nas regiões Norte, Centro-Oeste e Nordeste, apesar dos evidentes êxitos, ainda está muito distante de assegurar uma distribuição da produção científica menos concentrada na região Sudeste.

Ramalho e Madeira (2005) também estudaram a expansão da pós-graduação na 
área de Educação nas regiões Norte e Nordeste do Brasil e identificaram que entre os anos de 1990 até os anos de 2000 houve uma ampliação de programas de pós-graduação nessas regiões e que todos os estados possuem ou mestrado e/ou doutorado em Educação. Porém, passados pouco mais de 13 anos após a publicação desse estudo, os resultados da pesquisa que realizamos revelam que tal ampliação ainda não foi suficiente para elevar o número de teses e dissertações a patamares próximos da produção científica dos estados do Sudeste e Sul.
Os resultados da pesquisa também revelam que a região Centro-Oeste é a terceira região que reúne o maior número de trabalhos $(n=22)$, apesar de ocupar o segundo lugar em termos da população indígena. Em contrapartida, as regiões Sul e Sudeste, que juntas reuniram a maioria dos estudos ( $\mathrm{n}=122)$ são aquelas com baixa densidade populacional indígena.

A vinculação das IES de acordo com a dependência administrativa é mostrada na Figura 2.

Figura 2 - Distribuição das IES por dependência administrativa.

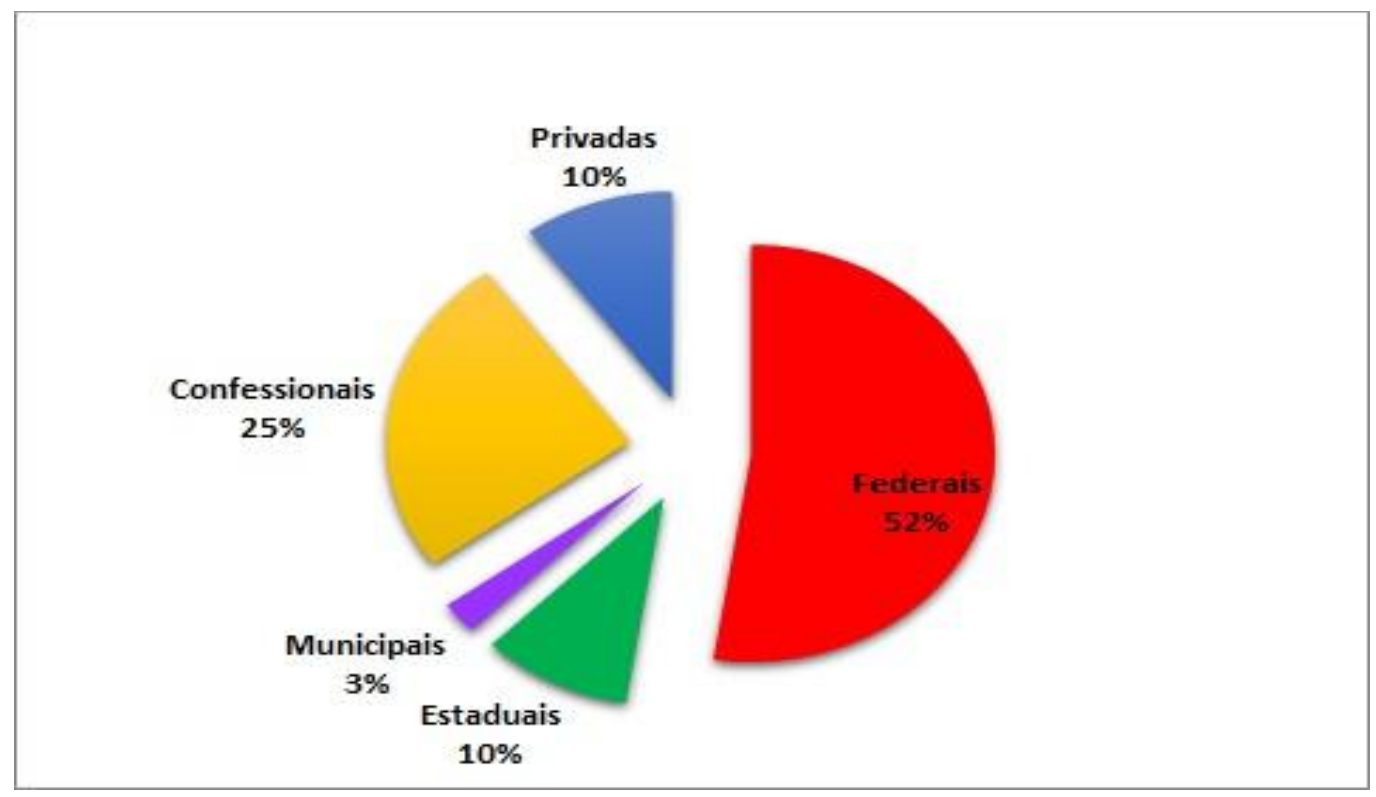

Fonte: Elaborada pelos autores.

Os resultados da Figura 2 apontaram que 66,6\% (n=26) das instituições são de natureza pública, isto é, universidades federais $(n=21)$, estaduais $(n=4)$, e apenas uma IES municipal. Ou seja, a produção científica em educação indígena no Brasil se concentra em sua maioria nas instituições públicas. Por sua vez, 33,3\% 
( $\mathrm{n}=13)$ são IES privadas, sendo que desse total a maioria $(n=10)$ são instituições de ensino superior de cunho confessional, isto é, mantidas por instituições religiosas. Esses achados refletem o crescimento da pós-graduação stricto sensu no setor privado no país.

Além disso, quando são cruzados os dados das IES confessionais com o total de trabalhos por instituição, os resultados revelam que essas dez IESs confessionais foram responsáveis por $20,8 \%$ do total de trabalhos $(n=173)$, sendo que a maioria está localizada na região Sudeste $(n=5)-$
PUC-SP; PUC-Campinas; UMESP; UPM;

UNISANTA - na região Sul $(n=3)$ - EST,

UNISINOS e PUC-RS - e na região

Centro-Oeste $(\mathrm{n}=1)$ apenas a UCDB.

\section{Autoria e orientação}

Os 173 trabalhos foram analisados buscando identificar as autorias $\mathrm{e}$ as orientações dos trabalhos. Os resultados apontaram a existência de 169 autores, uma vez que quatro deles realizaram trabalhos no nível mestrado e doutorado, conforme descrição no Quadro 1.

Quadro 1 - Autores que realizaram mestrado e doutorado sobre educação indígena.

\begin{tabular}{|c|c|}
\hline Autor/Área & Título dos trabalhos/Nível \\
\hline $\begin{array}{l}\text { Hellen Cristina Picanço } \\
\text { Simas }(2009 ; 2013)- \\
\text { Linguística }\end{array}$ & $\begin{array}{l}\text { Letramento indígena: entre o discurso do RCNEI e as práticas de letramento da } \\
\text { Escola Potiguara de Monte Mór.(mestrado) } \\
\text { Educação escolar yanomami e potiguara.(doutorado) }\end{array}$ \\
\hline $\begin{array}{l}\text { José Ivamilson Silva } \\
\text { Barbalho (2007; 2012) } \\
\text { - Educação }\end{array}$ & $\begin{array}{l}\text { Saberes da prática: tempo, espaço e sujeitos da formação escolar entre professores } x \\
\text { as indígenas do estado de PE. (mestrado) } \\
\text { Discurso como prática de transformação social: o político e o pedagógico na } \\
\text { educação intercultural Pankaká.(doutorado) }\end{array}$ \\
\hline $\begin{array}{l}\text { Neodir Paulo Travessini } \\
(2002 ; \quad \text { 2011) } \\
\text { Educação }\end{array}$ & $\begin{array}{l}\text { A questão da educação no contexto da modernidade e da civilização indígena. } \\
\text { (mestrado) } \\
\text { Ação comunicativa \& educação indígena intercultural e emancipatória: encontro } \\
\text { entre dois mundos possíveis? (doutorado) }\end{array}$ \\
\hline $\begin{array}{l}\text { Rita Gomes do } \\
\text { Nascimento (2006; } \\
\text { 2009) - Educação }\end{array}$ & $\begin{array}{l}\text { Educação escolar dos índios: consensos e dissensos no projeto de formação docente } \\
\text { Tapeba, Pitaguary e Jenipapo-Kanindé. (mestrado) } \\
\text { Rituais de resistência: experiências pedagógicas Tapeba (doutorado) }\end{array}$ \\
\hline
\end{tabular}

Fonte: Elaborado pelos autores.

Ao analisar os títulos e resumos dos trabalhos desses autores nota-se que as temáticas abordadas são semelhantes em ambos os trabalhos, ou seja, no mestrado os autores iniciaram esses estudos e aprofundaram a pesquisa em suas teses de doutoramento. Os dados do Quadro 1 também apontam que três autores realizaram sua formação em programas de pós-graduação de Educação e apenas um autor realizou o mestrado e doutorado em Linguística, reforçando assim a relação 
histórica de que a maioria dos trabalhos desta temática está diretamente ligada à área de Educação. orientadores dos 173 trabalhos, pois houve casos de orientadores que orientaram mais de um trabalho (Figura 3).

Em relação às orientações, os

resultados apontaram a existência de 128

Figura 3 - Distribuição dos orientadores e orientações.

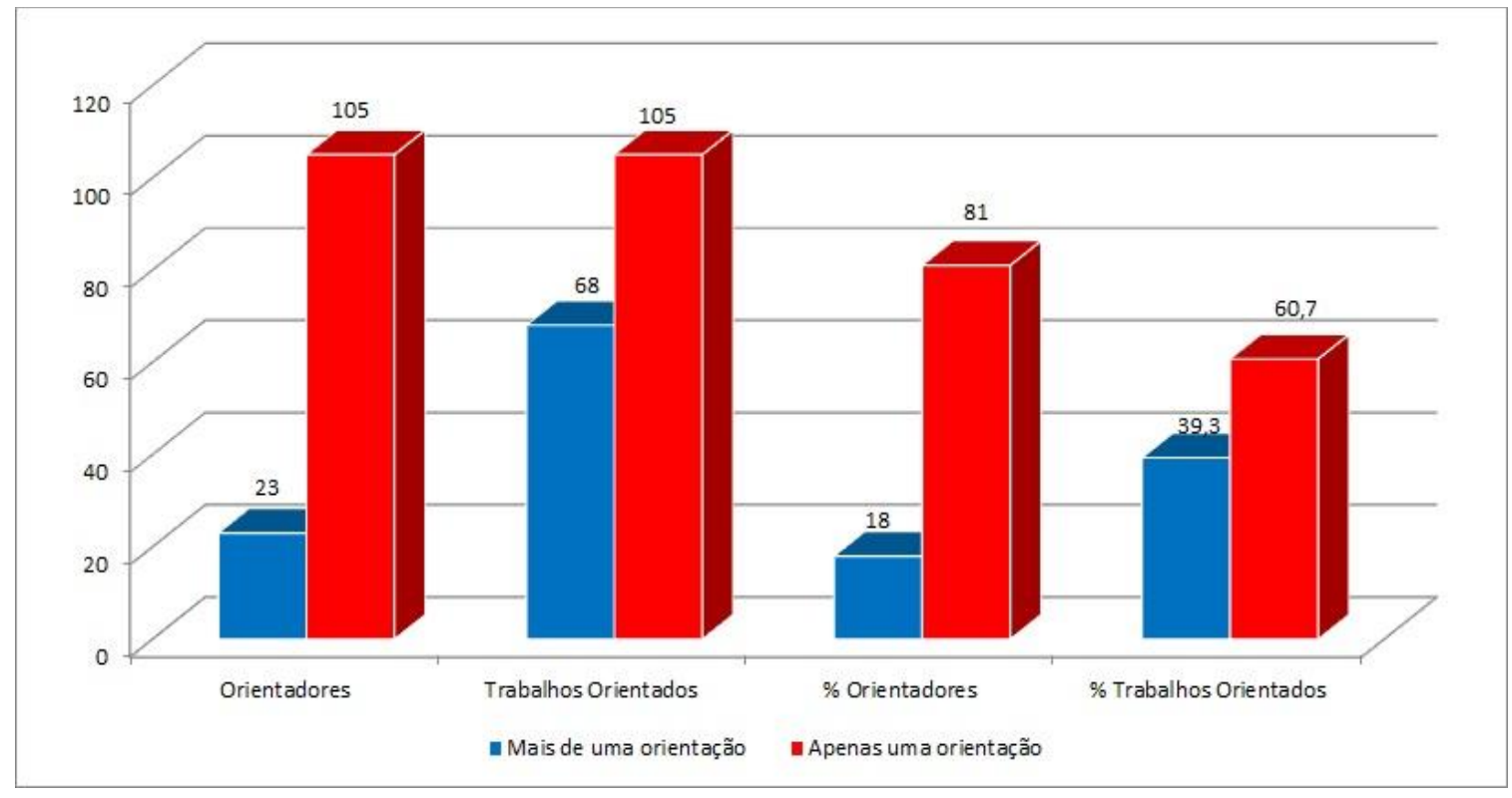

Fonte: Elaborada pelos autores.

Os resultados da Figura 3 mostram que um grupo de orientadores $(n=23)$ realizou mais de uma orientação (entre duas até nove), o que corresponde a 39,3\% do total de trabalhos orientados $(n=68)$. Os demais orientadores $(n=105)$ realizaram apenas uma orientação cada, o que corresponde a $60,7 \%$ do total de trabalhos. Para Momm (2009, p.86), "o total de orientações realizadas pode demonstrar o equilíbrio ou desequilíbrio entre os docentes dos programas de mestrado e doutorado, e, ainda, o grau de inserção ou de dispersão da produção do conhecimento científico no campo de estudo".

A Figura 4 apresenta a distribuição nominal dos orientadores com mais orientações $(n=23)$. 
Figura 4 - Orientadores com mais orientações.

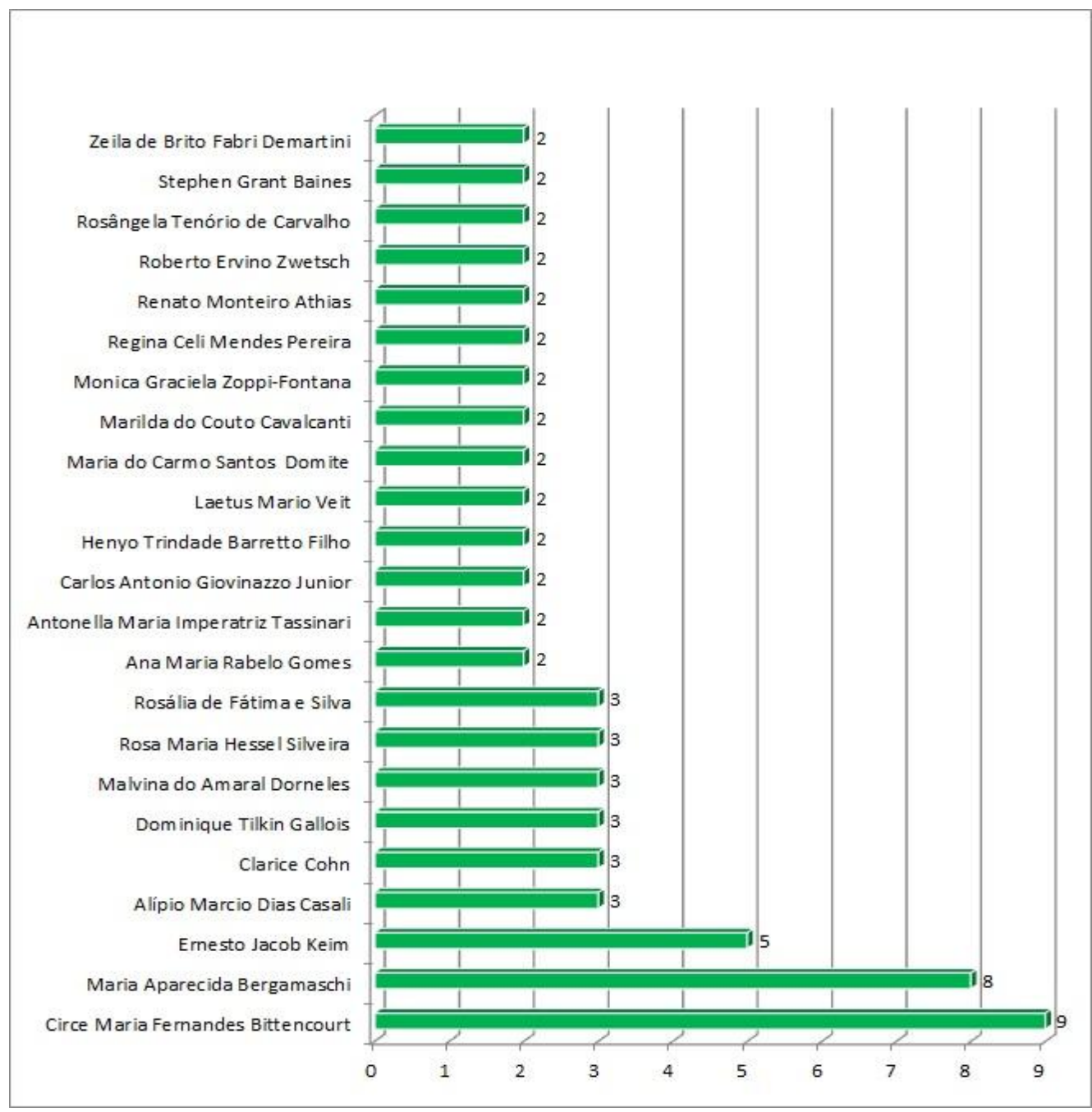

Fonte: Elaborada pelos autores.

A distribuição dos orientadores pode ser interpretada à luz de dois conceitosprincípios bibliométricos fundamentais da Lei de Lotka (1926): o núcleo, simbolizado pelos autores mais produtivos em uma área de conhecimento, e a dispersão, isto é, a grande diversidade de autores com pouca representação nessa mesma área. De acordo com os achados da pesquisa (Figura 4), enquanto que um grande grupo de orientadores é responsável pelo menor número de orientações $(\mathrm{n}=1)$, um pequeno grupo responde por mais orientações $(1<\mathrm{n}<10)$. Tais resultados, ao sinalizarem um grande distanciamento entre quem orienta apenas um trabalho daqueles que orientam mais de dois trabalhos, confirmam a Lei de Lotka que considera que alguns pesquisadores, supostamente de maior prestígio em uma determinada área 
do conhecimento, produzem muito e muitos pesquisadores, supostamente de menor prestígio, produzem pouco.

Para complementar os achados com relação aos orientadores mais profícuos $(n=23)$, foram levantados seus perfis acadêmicos por meio de consulta na plataforma de Currículos Lattes do CNPq (Quadro 2) visando buscar indícios de sua inserção no campo dos estudos sobre educação indígena.

Quadro 2 - Perfil acadêmico dos orientadores com mais orientações.

\begin{tabular}{|c|c|}
\hline $\begin{array}{l}\text { Orientadores / IES/ } \\
\text { Total de orientações }\end{array}$ & Perfil Acadêmico \\
\hline $\begin{array}{l}\text { Circe Maria Fernandes } \\
\text { Bittencourt }- \text { USP/PUC- } \\
\text { SP (9) }\end{array}$ & $\begin{array}{l}\text { Desenvolve pesquisa sobre ensino de História e História da Educação, em especial } \\
\text { sobre história da educação indígena. }\end{array}$ \\
\hline $\begin{array}{lr}\text { Maria } & \text { Aparecida } \\
\text { Bergamaschi } & - \text { UFRGS } \\
(8) & \end{array}$ & $\begin{array}{l}\text { Atua nas áreas Educação Indígena e Ensino de História, com pesquisas sobre } \\
\text { educação guarani, educação escolar indígena e a temática indígena na escola. } \\
\text { Participa da Rede Saberes Indígenas na Escola - Núcleo UFRGS. }\end{array}$ \\
\hline $\begin{array}{l}\text { Ernesto Jacob Keim - } \\
\text { FURB(5) }\end{array}$ & $\begin{array}{l}\text { Atua na área de Educação Escolar junto a povos indígenas, ancorado na abordagem } \\
\text { da Educação e Pedagogia Anticolonial. }\end{array}$ \\
\hline $\begin{array}{l}\text { Alípio Marcio Dias Casali } \\
\text { - PUC-SP (3) }\end{array}$ & $\begin{array}{l}\text { Atua na ênfase Currículo, Conhecimento, Cultura e Ética com foco no currículo em } \\
\text { escolas indígenas e formação de professores indígenas. }\end{array}$ \\
\hline $\begin{array}{l}\text { Clarice Cohn - UFSCar } \\
\text { (3) }\end{array}$ & $\begin{array}{l}\text { Atua na área de Antropologia, com ênfase em Etnologia Indígena e coordena o } \\
\text { Observatório da Educação Escolar Indígena da UFSCar. }\end{array}$ \\
\hline $\begin{array}{l}\text { Dominique Tilkin Gallois } \\
\text { - USP (3) }\end{array}$ & $\begin{array}{l}\text { Atua na área de Antropologia, com ênfase em Etnologia e História Indígena e } \\
\text { temas das tradições orais e cosmologias ameríndias, políticas indígenas, patrimônio } \\
\text { cultural e conhecimento tradicional. Presta assessoria a comunidades indígenas no } \\
\text { Amapá e Pará, e colabora com órgãos públicos e organizações não governamentais } \\
\text { em programas de formação indígena. }\end{array}$ \\
\hline $\begin{array}{l}\text { Malvina do Amaral } \\
\text { Dorneles }- \text { UFRGS (3) }\end{array}$ & $\begin{array}{l}\text { Atua na área de Gestão de Educação em temáticas da diversidade e formação } \\
\text { humana. }\end{array}$ \\
\hline $\begin{array}{ll}\text { Rosa } \quad \text { Maria } & \text { Hessel } \\
\text { Silveira } & \text { UFRGS (3) }\end{array}$ & $\begin{array}{l}\text { Atua nos temas: Estudos Culturais, identidade, diferença, literatura infanto-juvenil, } \\
\text { representações docentes, discursos, leitura e produção textual. }\end{array}$ \\
\hline $\begin{array}{l}\text { Rosália de Fátima e Silva } \\
\text { - UFRN ( }\end{array}$ & $\begin{array}{l}\text { Áreas de interesse: Metodologia da pesquisa e do ensino superior; Fundamentos } \\
\text { Históricos e Filosóficos da Educação Brasileira. }\end{array}$ \\
\hline $\begin{array}{l}\text { Ana Maria Rabelo Gomes } \\
\text { - UFMG (2) }\end{array}$ & $\begin{array}{l}\text { Atua na área de Antropologia e Educação nas temáticas: educação indígena, cultura } \\
\text { escolar, cultura e escolarização, aprendizagem e cultura. Lidera o grupo de pesquisa } \\
\text { em Educação Indígena. }\end{array}$ \\
\hline $\begin{array}{lr}\text { Antonella } & \text { Maria } \\
\text { Imperatriz } & \text { Tassinari } \quad- \\
\text { UFSC (2) } & \end{array}$ & $\begin{array}{l}\text { Atua na área de Antropologia, com ênfase em Etnologia Indígena, em temáticas } \\
\text { sobre: povos indígenas, infância e educação indígenas, identidade étnica, } \\
\text { diversidade cultural e educação escolar. Desenvolve projetos de pesquisa e } \\
\text { extensão vinculados ao NEPI (Núcleo de Estudos de Povos Indígenas) }\end{array}$ \\
\hline \begin{tabular}{lr|} 
Carlos & Antonio \\
Giovinazzo Junior - PUC- \\
SP (2)
\end{tabular} & $\begin{array}{l}\text { Atua na área de Educação e Sociologia nas temáticas das políticas educacionais e } \\
\text { culturais articuladas aos processos de escolarização, privilegiando estudos sobre } \\
\text { escolas de comunidades indígenas. }\end{array}$ \\
\hline $\begin{array}{l}\text { Henyo Trindade Barretto } \\
\text { Filho - UnB (2) }\end{array}$ & $\begin{array}{l}\text { Atua nas áreas de Antropologia e Ciências Ambientais, com foco nas temáticas dos } \\
\text { povos indígenas, políticas indigenista e ambiental, meio ambiente e unidades de } \\
\text { conservação, gestão territorial e ambiental. }\end{array}$ \\
\hline
\end{tabular}

\begin{tabular}{|l|c|c|c|c|c|c|c|}
\hline Rev. Bras. Educ. Camp. & Tocantinópolis & v. 2 & n. 2 & p. $677-707$ & jul../dez. & 2017 & ISSN: 2525-4863 \\
\hline
\end{tabular}




\begin{tabular}{|c|c|}
\hline etus Mario Veit & $\begin{array}{l}\text { utor em História pela Université Catholique de Louvain (1973) e pel } \\
\text { niversidade Gregoriana de Roma (1960). }\end{array}$ \\
\hline io & a. \\
\hline da do & $\begin{array}{l}\text { mas da leitura, letramentos, identidades, diversidade/diferença, formação d } \\
\text { ofessores. }\end{array}$ \\
\hline ica $\mathrm{Gr}$ & $\begin{array}{l}\text { ibjetivação, em parti } \\
\text { iguísticas e da argume }\end{array}$ \\
\hline a & $\begin{array}{l}\text { ua na área de Lir } \\
\text { cente e processos de }\end{array}$ \\
\hline ro Athias - & 1. \\
\hline to Ervino Zwetsch - & 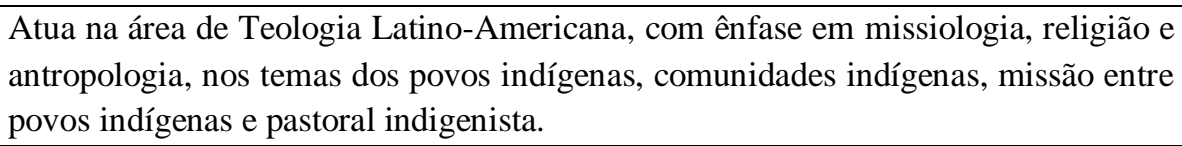 \\
\hline $\begin{array}{ll}\text { gela } & \text { Tenório } \\
\text { ho }\end{array}$ & a. \\
\hline rant Baines & $\begin{array}{l}\text { tua na área de Antropologia e Etnologia Indígena. Realizou pesquisas sol } \\
\text { ipactos de grandes projetos de desenvolvimento em povos indígenas, etnicidad } \\
\text { cionalidade entre povos indígenas em fronteiras internacionais, polít } \\
\text { digenista, indigenismo. }\end{array}$ \\
\hline 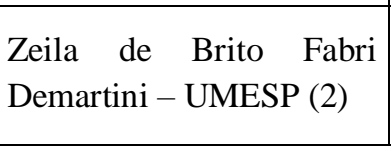 & 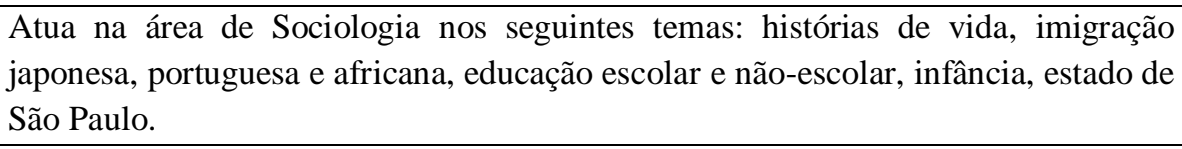 \\
\hline
\end{tabular}

Fonte: Elaborado pelos autores.

Como se vê no Quadro 2, o perfil acadêmico dos orientadores mais profícuos $(\mathrm{n}=23)$ é difuso, pois alguns realizam investigações com a temática educação indígena ao longo de seu percurso acadêmico e atuação em órgãos e instituições voltadas à causa indígena, enquanto que o perfil de outros orientadores sugere que o escopo de suas pesquisas não está alinhado com as temáticas indígenas, fornecendo indícios de que as orientações realizadas com essa temática podem ter ocorrido muito mais em virtude das escolhas pessoais dos mestrandos e doutorandos e não pela aderência dos orientadores ao tema.

Ao analisar a vinculação desses orientadores aos programas de pósgraduação verifica-se que a maioria $(n=13)$ é da área de Educação, seguidos pelos da Antropologia $(n=5)$, Linguística $(n=3)$, Teologia $(n=1)$ e Desenvolvimento Sustentável $(\mathrm{n}=1)$, o que parece confirmar o argumento de Silva (2016, p. 22) de que

... embora a maioria dessas teses e dissertações tenha sido realizada em programas de pós-graduação da área 
de Educação cujo objeto devesse versar fundamentalmente sobre o ensino didático-pedagógico, no entanto, a rigor, estão focadas nas dimensões culturalistas e/ou linguísticas. Assim a tríade Educação, Antropologia e Linguística são as áreas que têm dominado os estudos sobre educação escolar indígena.

Os achados também dialogam com as visões de Capacla (1995), Grupioni (2008) e Cavalcanti-Schiel (1999), confirmando o argumento deste autor de que

A franca maioria dos trabalhos investigativos já realizados no Brasil sobre escolarização de índios foi constituída de incursões acadêmicas (ou reorientações para o campo acadêmico) de carreiras pessoais de agentes diretamente envolvidos com a causa da educação escolar para índios (Cavalcanti-Schiel, 1999, p. 5. Grifo do autor).

Também foi investigado se os orientadores $(\mathrm{n}=128)$ possuem bolsa de produtividade em pesquisa do $\mathrm{CNPq}$, pois de acordo com Cavalcanti e Pereira (2008) essa é uma modalidade atribuída a pesquisadores de reconhecida competência, com produção científica regular de valor reconhecido pelos pares, atuação na formação de recursos humanos em cursos de pós-graduação e desempenho de atividades de natureza científica e acadêmica.

A prospecção no currículo Lattes dos orientadores mais profícuos $(n=23)$ revelou que $43,4 \% \quad(n=12)$ são bolsistas de produtividade em pesquisa nos níveis 2 $(n=6)$ e $1 \quad(n=6)$, enquanto que entre os demais orientadores, apenas $15,2 \%(n=13)$ possuem esse tipo de bolsa nos níveis 2 $(n=7)$ e $1(n=6)$.

\section{As etnias abordadas nas teses e dissertações}

Estima-se que existam no Brasil 305 etnias indígenas vivendo dentro e/ou fora de suas terras (IBGE, 2016). Esses dados suscitaram o interesse em verificar quais etnias foram estudadas nos 173 trabalhos analisados, conforme mostram os dados da Tabela 3.

Tabela 3 - Distribuição das etnias estudadas nas dissertações e teses.

\begin{tabular}{|c|c|c|c|}
\hline Etnias & Etnias & T\&D* & Total \\
\hline Guarani & 1 & 18 & 18 \\
\hline Terena; Kaingang; Guarani Mbyá & 3 & 12 & 36 \\
\hline Tikuna & 1 & 8 & 8 \\
\hline Karipuna; Kaiowá; Baniwa & 3 & 5 & 15 \\
\hline Xacriabá; Tupi-Guarani; Surui; Paresi; Makurap; Gavião; Arara & 7 & 4 & 28 \\
\hline $\begin{array}{l}\text { Baré; Xokleng; Xavante; Uru Eu Wau Wau; Tupinikim; Tapirapé; Krenak; } \\
\text { Kaxinawá;Canoe }\end{array}$ & 9 & 3 & 27 \\
\hline
\end{tabular}




\begin{tabular}{|c|c|c|c|}
\hline $\begin{array}{l}\text { Yanomami; Xikrin Mebengokré; Wapichana; Tukano; Tariana; Tapuia; } \\
\text { Tapeba; Potiguara; Pataxó; Pankararu; Pankará; Oro Win; Oro Waram } \\
\text { Xijein; Oro Waram; Oro Não; Oro Eu; Oro At; Makuxi; Kinikinau; Kayabi; } \\
\text { Karitiana; Karajá; Kalapalo; Kadiwéu; Guarani; Nandeva; Guajajara; } \\
\text { Gavião-Ikolem; Djeoromitxí (Jaboti); Cinta Larga; Chiquitano; Campé; } \\
\text { Cabixi; Bakairi; Atikum; Asurini; Aruá; Apinajé; Amondawa }\end{array}$ & 38 & 2 & 76 \\
\hline $\begin{array}{l}\text { Zoró, Yawanawá, Yawalapiti, Xukuru, Xucuru-Karirí, Xipaia, Xikrin, } \\
\text { Xerente, Waurá, Waradzu, Wajãpi, Waimiri-Atroari, Waiãpi, Wai Wai, } \\
\text { Umutina, Tuyuka, Tuparí, Tenharin, Tembé, Tauarepang, Suyá, Suruí } \\
\text { Paiter, Sawaitê, Sabanê, Rikbaktsa, Puruborá, Pitaguary, Piratapuia, Pataxó } \\
\text { Hãhãhãi, Parakanã, Panará, Oro Wari, Oro Waje, Oro Mon, Oro Bom, } \\
\text { Ofaié, Nasa, Nambiquara, Nafukuá, Nadëb, Migueleno, Mayrob, } \\
\text { Manchineri, Mamaidé, Latundê, Kyikatêjê, Kuikuro, Kuazar, Krikatí, } \\
\text { Krahô, Kotiria (Wanano), Kiriri, Kaxararí, Katukina, Katitaurlu, Kararaô } \\
\text { Kaparuá, Kanamari, Kampé, Kamba, Kamaiurá, Juruna, Jiripancó, } \\
\text { Jenipapo-Kanindé, Jaminawa, Irantxe, Ikrin, Ikpeng, Guató, Guarani } \\
\text { Kaiowá, Gavião Parkatêjê, Gavião Akrãtikatêjê, Galibi-Marworno, } \\
\text { Dessano, Curuaia, Cassupá, Cao Oro At, Bororo, Borari, Aweti, Avá- } \\
\text { Guarani, Ashaninka, Arikapú, Araraweté, Arara-Karo, Arara Shawãdawa, } \\
\text { Arapium, Apyãwa, Apurinã, Apiaká, Amanayé, Aikinã }\end{array}$ & 92 & 1 & 92 \\
\hline Total & 154 & & $300 * *$ \\
\hline
\end{tabular}

(*) T\&D - Teses e dissertações; (**) Cada trabalho pode ter abordado mais de uma etnia.

Fonte: Elaborada pelos autores.

Os resultados da Tabela 3 mostram que foram estudadas 154 etnias, o que representa $50,5 \%$ do total estimado de etnias existentes no país, revelando que metade desse total ainda não se constituiu em objeto de estudo em trabalhos que abordam a educação indígena.
De acordo com a distribuição geográfica das etnias (Quadro 3) verificase que as etnias Guarani e Guarani Mbyá estão presentes na maior parte das regiões do país distribuídas em nove estados.

Quadro 3 - Distribuição geográfica das etnias.

\begin{tabular}{|c|c|c|}
\hline Etnias & Regiões & Estados \\
\hline Guarani e Guarani Mbyá & Norte, Centro-Oeste, Sudeste, Sul. & $\begin{array}{c}\text { PA, TO, MS, ES, SP, RJ, SC, PR, } \\
\text { RS }\end{array}$ \\
\hline Terena & Centro-Oeste e Sudeste & MS, MT, SP \\
\hline Kaingang & Sul e Sudeste & PR, RS, SC, SP \\
\hline Tikuna & Norte & AM \\
\hline
\end{tabular}

Fonte: Elaborado pelos autores.

Entre as etnias mais estudadas, com $6 \%(\mathrm{n}=18)$ do total de trabalhos $(\mathrm{n}=300)$ encontraram-se os Guarani, seguidos pelos trabalhos $(n=12)$ que focalizaram as etnias Terena, Kaingang, Guarani Mbyá $(n=12)$ e os Tikunas $(\mathrm{n}=8)$. Os Guarani e os 
Guarani Mbyá reúnem uma população atual de 68.457 indivíduos (Brasil, 2010) e sua família linguística é o Tupi-Guarani, sendo que apenas a região Nordeste do país não possui povos dessa etnia em seu território. Por estarem em praticamente todas as regiões brasileiras, justifica-se o maior interesse das pesquisas em educação escolar indígena estudar tal etnia. Além disso, aparecem em maior incidência nos estudos, pois são os povos que mais desenvolveram os processos de escolarização em seu meio (Bergamaschi, 2012).

Contudo, apesar da etnia Tikuna ter sido bastante estudada, nem todos os pesquisadores de pós-graduação interessados nos estudos escolares indígenas desta etnia estão realizando suas pesquisas no Amazonas, localizado na região de origem destes povos. Isso pode indicar que os programas de pós-graduação da região Norte ainda não possuem áreas ou linhas de pesquisa para atender a esta demanda das pesquisas ou mesmo que não possuem docentes com a experiência e interesse por estas etnias em seu quadro geral de pesquisadores.

\section{Considerações finais}

As teses e dissertações sobre educação indígenas disponíveis na
BDTD/IBICT se referem ao período entre 1996 e 2016. Nesse recorte temporal de 21 anos foram produzidos 173 trabalhos, ou seja, uma média de 8,65 trabalhos por ano. Dos 173 trabalhos analisados, nota-se que há uma prevalência para as dissertações oriundas de mestrado acadêmico, seguido de teses de doutorado e, quase incipiente, de mestrado profissional.

Dos 128 diferentes orientadores que orientaram os trabalhos, a maior concentração recaiu em apenas três pesquisadores: Circe Maria Fernandes Bittencourt, Maria Aparecida Bergamaschi e Ernesto Jacob Keim, que orientam pesquisas com a temática indígena na área de Educação. Por outro lado, encontra-se um grupo significativo de orientadores com baixa frequência de orientações, alguns deles recém entrados ao campo e outros que nunca orientaram pesquisas e/ou trabalhos sobre essa temática.

Em relação ao total de teses e dissertações sobre educação indígena, os resultados mostraram que a área de Educação é majoritária, com 58,4\% $(n=101)$ trabalhos defendidos em programas de pós-graduação dessa área. Os demais $41,6 \%(n=72)$ foram realizados em programas de pós-graduação de 16 diferentes áreas de conhecimento, com média de 4,5 trabalhos por área do conhecimento, sendo que duas áreas se 
destacaram: a Antropologia, com 15 trabalhos, e a Linguística, com 11 trabalhos. Esses resultados demonstram que a temática da educação indígena é interdisciplinar, todavia pode-se inferir que são as três áreas majoritárias - Educação, Antropologia e Linguística - que predominam nesse campo de estudos.

Ainda que a Antropologia e a Linguística tenham se destacado entre as áreas de conhecimento que produziram trabalhos de pós-graduação sobre a educação indígena, todavia o foco das pesquisas realizadas nessas áreas recaiu mais sobre os aspectos culturais $\mathrm{e}$ linguísticos das populações indígenas do que sobre a educação indígena propriamente dita. No caso da Antropologia, concorda-se, portanto, com o argumento vindo de uma antropóloga (Tassinari, 2008), de que as contribuições da etnologia indígena versaram sobre tipologias das sociedades, culturas e processos históricos das populações indígenas, desconsiderando os fenômenos próprios da educação da transmissão de saberes, dos processos nativos de ensino e aprendizagem.

Com relação às regiões do país nas quais estão localizados os programas de pós-graduação em que foram defendidos os 173 trabalhos analisados, os resultados mostraram uma proporção desigual entre as cinco regiões brasileiras, tendo a região Sudeste como a que concentrou o maior número de trabalhos. Apesar da região Norte do Brasil possuir o maior número de etnias indígenas, a mesma é praticamente incipiente $(1,7 \%)$ com relação ao volume global de teses e dissertações defendidas sobre a educação indígena.

Das 39 IES identificadas na pesquisa, as universidades públicas são as que mais produziram teses e dissertações sobre educação indígena e por mais pulverizada que seja a distribuição de trabalhos entre as IES brasileiras, é desproporcional o volume de defesas entre as Instituições públicas e as Instituições privadas. Destacam-se com maior número de trabalhos respectivamente a Universidade Federal do Rio Grande do Sul, a Pontifícia Universidade Católica de São Paulo e a Universidade de São Paulo, que juntas produziram 59 teses ou dissertações, representando $34,1 \%$ do total.

Os resultados também mostraram que as 154 etnias estudadas nas teses e dissertações cobrem 50,5 \% do total de 305 existentes no país, denotando uma lacuna expressiva em relação às demais. Entre as etnias mais estudadas, destacam-se a Guarani, presente em 18 trabalhos, seguida pelas etnias Terena, Kaingang, Guarani Mbyá, cada uma com 12 trabalhos e os Tikuna com 8 trabalhos. 
Finalmente, os resultados desse estudo bibliométrico demonstram que apesar de um volume significativo de trabalhos sobre educação indígena no país, ainda há muito a ser pesquisado nos programas brasileiros de pós-graduação.

\section{Referências}

Alves, J. P. (2002). Novos atores e novas cidadanias: o reconhecimento dos direitos dos povos indígenas a uma educação escolar específica, diferenciada, intercultural e bilíngue/multilíngue. In: Marfan, M. A. (Org.). In Anais II do Congresso brasileiro de qualidade na educação: formação de professores: educação indígena, Brasília, 2002.

André, M. E. D. A. (2009). A produção acadêmica sobre formação de professores: um estudo comparativo das dissertações e teses defendidas nos anos 1990 e 2000. Formação Docente, 1(1), 41-56.

Araújo, S. A. (2014). A criança indígena nos estudos acadêmicos no Brasil: uma análise das produções científicas (20012012). (Dissertação de Mestrado). Universidade Federal do Pará, Pará.

Bergamaschi, M. A. (2012). Processos e práticas educativas dos povos ameríndios no Brasil: um olhar a partir de pesquisas contemporâneas. Arquivos analíticos de políticas educativas, 20(34).

Bittar, M., \& Ferreira Jr. A. (2007). Casas de bâ-á-bá e colégios jesuíticos no Brasil do século 16. Em Aberto, 21, 33-57.

Brasil. (2010). Instituto Brasileiro de Geografia e Estatística. Censo Demográfico 2010: características gerais dos indígenas: resultados do universo. Rio de Janeiro: IBGE.

Calderón, A. I., \& Ferreira, A. G. (2011). Administração da educação no Brasil: um diálogo comparativo com as tendências temáticas da Revista Ibero-Americana de Educação. Revista Brasileira de Política e Administração em Educação, 27(2), 321339.

DOI:

http://dx.doi.org/10.21573/vol27n22011.24 $\underline{776}$

Capacla, M. V. (Org.). (1995). O debate sobre a educação indígena no brasil (1975-1995): resenhas de teses e livros. Brasília: MEC.

CAPES. (2017). Tabelas de áreas do conhecimento. Recuperado de http://www.capes.gov.br/avaliacao/instrum entos-de-apoio/tabela-de-areas-doconhecimento-avaliacao.

Cavalcanti-Schiel, R. A. (1999). Presente de Branco, presente de Grego? (Dissertação de Mestrado) Universidade Federal do Rio de Janeiro.

Cavalcanti, A. L., \& Pereira, D. S. A. (2008). Perfil do bolsista de produtividade em pesquisa do Conselho Nacional de Desenvolvimento Científico e Tecnológico (CNPq) na área de Odontologia. Revista Brasileira de Pós-Graduação, 5(9), 67-88. DOI: $\quad$ http://dx.doi.rg/10.2171/23582332.2008.v5.142

Clímaco, J. C. T. S., Neves, C. M. de C., \& Lima, B. F. Z. (2012). Ações da Capes para a formação e a valorização dos professores da educação básica do Brasil e sua interação com a pós-graduação. Revista Brasileira de Pós Graduação, 9(16), 181-209.

DOI: http://dx.doi.org/10.21713/23582332.2012.v9.286 
D'angelis, W. R. (2008). Educação escolar indígena? A gente precisa ver. Ciência $e$ Cultura, 60(4), 28-31.

Faria, M. R. (2016). Pedagogia da vigilância: o jesuíta na aldeia (séculos XVI e XVII). Cadernos de Pesquisa, 46(162), 1010-1026.

DOI: http://dx.doi.org/10.1590/198053143816

Féres-Carneiro, T., Bastos, A. V., Feitosa, M. A. G., Moura, L. M. S., \& Yamamoto, O. H. (2010). Lacunas, metas e condições para a expansão da Pós-Graduação em Psicologia no País. Psicologia: Reflexão e Crítica, 23(1), 11-24.

Ferraz, I. T., \& Domingues, E. (2016). A Psicologia Brasileira e os Povos Indígenas: Atualização do Estado da Arte. Psicologia: Ciência e Profissão, 36(3), 23-31. DOI: 10.1590/1982-3703001622014

Fontes, T. F. (2016). Por uma geografia indígena: uma análise do ensino de geografia nas licenciaturas indígenas interculturais da Universidade Federal do Amazonas. (Dissertação de Mestrado). Universidade Federal do Amazonas, Amazonas.

Geocapes. (2016). Distribuição de Programas de Pós-graduação no Brasil por Estado. Brasília: CAPES.

Grupioni, L. D. B. A (2003). Educação Indígena na Academia: inventário comentado de dissertações e teses sobre educação escolar indígena no Brasil (19782002). Em Aberto 20(76), 197-238. DOI: http://dx.doi.org/10.24109/2176-

6673.emaberto.20i76.2192

Grupioni, L. D. B. (2008). Olhar longe, porque o futuro é longe: cultura, escola e professores indígenas no Brasil. (Tese de Doutorado). Universidade de São Paulo, São Paulo.
Grupioni, L. D. B. (2013). Quando a Antropologia se defronta com a Educação: formação de professores índios no Brasil. Pro-Posições, 24(2), 69-80. DOI: http://dx.doi.org/10.1590/S010373072013000200006

Guimarães, I. P., Bulhões, R., Massao, C. R., \& Hayashi, M. C. P. I. (2015). Avaliação da pós-graduação no Brasil: como superar a imprecisão que reina entre nós. Quaestio: revista de estudos de educação, 17, 87-119.

INEP. (2016). Censo 2010. Recuperado de: http://censo2010.ibge.gov.br/

INEP. (2013). Censo da educação básica: 2012: resumo técnico. Brasília: MEC.

Kahn, M., \& Franchetto, B. (1994). Educação indígena no Brasil: conquistas e desafios. Em Aberto, 14(63), 16-34. DOI: http://dx.doi.org/1024109/21766673.emaberto.14i63.1972.

Lotka, J. L. (1926). The frequency distribution scientific productivity. Journal of the Washington Academy of Sciences, 16(12), 317-323.

Luciano, G. J. S. (2011). Educação para manejo e domesticação do mundo entre a escola real e a escola ideal: os dilemas da educação escolar indígena no Alto Rio Negro. (Tese de Doutorado). Universidade de Brasília, Brasília.

Magalhães, G. B., \& Landim Neto, F. O. (2013). A geografia e a educação indígena: uma análise dos documentos normativos. Revista Brasileira de Educação Geográfica, 3(5), 82-97.

Momm, C. F. (2009). O conhecimento científico em Turismo no Brasil. (Dissertação de Mestrado). Universidade Federal de Santa Catarina, Santa Catarina. 
Oliveira, A. D., \& Zibetti, M. L. T. (2015). $\mathrm{O}$ que pesquisas brasileiras sobre educação escolar indígena revelam? Revista Tellus, 29, 87-112. DOI: http://dx.doi.org/1020435/tellus.v0i29.361

PUC. Pontifícia Universidade Católica de São Paulo. (2017). Linhas de pesquisa. Recuperado de: http://www.pucsp.br/posgraduacao/mestrado-e-

doutorado/educacao-historia-politica-

sociedade

Ramalho, B. L., \& Madeira, V. P. C. (2005). A pós-graduação em educação no Norte e Nordeste: desafios, avanços e perspectivas. Revista Brasileira de Educação, 30, 70-81. DOI: http://dx.doi.org/10.1590/S141324782005000300006

Silva, A. R. (2016). Concepções e práticas de educação escolar indígena: institucionalidade, estado da arte $e$ escolarização dos Tikuna no Alto Solimões-AM. (Tese de Doutorado). Universidade Federal do Amazonas, Amazonas.

Silva, M. R., Hayashi, C. R. M., \& Hayashi, M. C. P. I. (2011). Análise bibliométrica e cientométrica: desafios para especialistas que atuam no campo. InCID: Revista de Ciência da Informação e Documentação, 2(1), 110-129. DOI: http://dx.doi.org/10.11606/issn21782075.v2ilp.110-129.

Souza, I. C. R. S., \& Bruno, M. M. G. (2015). Educação escolar indígena: a escola que temos e a escola que queremos. In Anais do I Congresso de educação da Grande Dourados, Dourados.

Souza, J. P., \& Pereira, L. B. (2002). Pósgraduação no Brasil: análise do processo de concentração. Acta Scientiarum Human and Social Sciences, 24(1), 159-166. DOI: http://dx.doi.org/10.4025/actascihumansoc. v24i0.2431

Tassinari, A. M. I. (2001). Escola indígena: novos horizontes teóricos, novas fronteiras de educação. In Silva, A. L., \& Ferreira, M. L. Antropologia, história e educação. São Paulo, Global.

Tassinari, A. M. I. (2008). A educação escolar indígena no contexto da antropologia brasileira. Ilha: revista de antropologia, $\quad 10(1), \quad 67-78$. DOI: http://dx.doi.org/10.5007/2175-

8034.2008v10n1p217

UFRGS. Universidade Federal do Rio Grande do Sul. (2017). Linhas de pesquisa. Recuperado de: http://www.ufrgs.br/ppgedu/linhas.html

\footnotetext{
${ }^{\mathrm{i}}$ De acordo com a CAPES, há 2.031 programas de pós-graduação que oferecem conjuntamente os níveis mestrado e doutorado e 603 programas de mestrado profissional (Geocapes, 2016).

ii Para a distribuição dos trabalhos nas áreas de conhecimento foi utilizada a Tabela de Áreas de Conhecimento e Avaliação da CAPES (2017).
}

Recebido em: 17/08/2017 Aprovado em: 17/09/2017 Publicado em: 28/10/2017 
Como citar este artigo / How to cite this article / Como citar este artículo:

APA:

Maroldi, A. M., Lima, L. F. M., Hayashi, C. R. M., \& Hayashi, M. C. P. I. (2017). Panorama bibliométrico das teses e dissertações sobre educação indígena. Rev. Bras. Educ. Camp., 2(2), 677-707. DOI: http://dx.doi.org/10.20873/uft.2525-

$\underline{4863.2017 \mathrm{v} 2 \mathrm{n} 2 \mathrm{p} 677}$

ABNT:

MAROLDI, A. M., LIMA, L. F. M., HAYASHI, C. R. M., \& HAYASHI, M. C. P. I. Panorama bibliométrico das teses e dissertações sobre educação indígena. Rev. Bras. Educ. Camp., Tocantinópolis, v. 2 , n. 2, p. 677-707, 2017. DOI: http://dx.doi.org/10.20873/uft.2525$\underline{4863.2017 \mathrm{v} 2 \mathrm{n} 2 \mathrm{p} 677}$

\section{ORCID}

Alexandre Masson Maroldi

iD http://orcid.org/0000-0002-6592-7750

Luis Fernando Maia Lima

iD http://orcid.org/0000-0002-4208-4914

Carlos Roberto Massao Hayashi

iD http://orcid.org/0000-0003-1481-5545

Maria Cristina Piumbato Innocentini Hayashi

iD http://orcid.org/0000-0003-1250-3767 